\title{
Örgüt Kültürünün Örgütsel Bağlılığa Etkisi: Sağlık Sektöründe Bir Araştırma
}

\author{
DOI: 10.26466/opus.858804
}

*

\section{Gülșah Gençer Celik *}

* Dr. Öğr. Üyesi, Beykent Üniversitesi, Meslek Yüksekokulu, İşletme Yönetimi Bölümü E-Posta: gulsahg@beykent.edu.tr

ORCID: $\underline{0000-0001-8610-3673}$

\section{Öz}

Çalışanların hangi sebeple olursa olsun örgütte kalmaya gönüllü olmaları örgütlerin bulundukları sektörde rekabet edebilmelerine katkı sağlayacaktır. Araştırmanın amacı, örgüt kültürünün sağglk sektöründeki çalışanların örgütsel bağhllı̆̆ına etkisinin tespit edilmesidir. Araştırmanın örneklemi İstanbul'da sağlık sektöründe yer alan 259 hemşiredir. Araştırma verilerinin toplanmasında anket formlar kullanılmıştır. Araştırma verileri SPSS 25 paket programı ile analiz edilmiştir. Verilerin analizinde sırası ile faktör analizi, güvenilirlik analizi, tanımlayıcı istatistikler, korelasyon analizi ve regresyon analizleri kullanılmıştır. Korelasyon analizi sonucuna göre; örgüt kültürü ile örgütsel bağhllık alt boyutlar arasında pozitif yönde ve istatistiki olarak anlamlı ilişkiler tespit edilmiştir. Sadece ödüllendirme kültürü ile devam bağhllı̆̆ arasında anlamlı bir ilişkiye rastlanamamıştır. Regresyon analizi sonuçlarına göre; algllanan örgüt kültürü çalışanların örgütsel bağhllıklarını arttırmaktadır. Ayrıca iletişim ve destek kültürü ile ödüllendirme kültürü çalışanların duygusal ve normatif bağhllıkların olumlu yönde etkilemektedir. Bunun yanında, iletişim ve destek kültürü çalışanların devam bağhllı̆̆ını arttırmaktadır. Araştırma sonunda, örgütlerin çalışanların bă̆lılığını arttırmasında örgüt kültürünün hangi unsurlar üzerine odaklanması gerektiği hakkında öneriler sunulmuştur.

Anahtar Kelimeler: Örgüt kültürü, Örgütsel bağlllık, Sağglk sektörü 


\title{
The Effect of Organizational Culture on Organizational Commitment: A Research in Health Sector
}

\begin{abstract}
Employees 'willingness to stay in the organization for whatever reason will contribute to the organizations' ability to compete in their sector. The research aims to determine the effect of organizational culture on the organizational commitment of employees in the health sector. The sample of the study is 259 nurses from the health sector in Istanbul. Questionnaire forms were used to collect research data. The data of the research were analyzed with SPSS 25 package program. Factor analysis, reliability analysis, descriptive statistics, correlation analysis, and regression analysis were used to analyze the data, respectively. According to correlation analysis, positive and statistically significant relationships were found between organizational culture and organizational commitment sub-dimensions. No significant relationship was found only between the rewarding culture and attendance commitment. According to regression analysis results; perceived organizational culture increases the organizational commitment of employees. Also, communication and support culture and rewarding culture positively affect employees' emotional and normative commitment. Besides, communication and support culture increases the attendance commitment of the employees. At the end of the research, suggestions were presented on which elements the organizational culture should focus on to increase the employees' commitment.
\end{abstract}

Keywords: Organizational culture, organizational commitment, health sector 


\section{Giriş}

Örgütlerin rekabet avantajı elde etmesinde ve sürdürmesinde çalışanların önemli bir yere sahip olduğu bilinmektedir. Çalışanların yeteneklerinin örgüt bünyesinde muhafaza edilmesi bu açıdan önem taşımaktadır. Çalışanların örgüt içerisinde kalmalarının bir yolu onların örgüte olan bağlllıklarının arttırılması yoluyla gerçekleşmektedir. Öyle ki; çalışanların hangi sebeple olursa olsun örgütte kalmaya gönüllü olmaları örgütlerin bulundukları sektörde rekabet edebilmelerine katkı sağlayacaktır.

Alanyazında yer alan çalışma sonuçlarına göre örgütlerin kültürleri, çalışanların örgüte olan bağlılığını arttıran bir unsundur (Gülova ve Demirsoy, 2012; Demir ve Öztürk, 2011; Çavuş ve Gürdoğan, 2008; Diker, 2014). Bu çalışmalarda örgütlerin kültürel özelliklerinin çalışanların duygusal açıdan, ilkeler (normlar) açısından ya da alternatiflerin yokluğu açısından örgüte olan bağlılıklarını olumlu yönde etkilediği sonucuna ulaşılmıştır. Bununla birlikte son yıllarda iletişim teknolojilerinin gelişmesi ve çalışanların diğer örgütlerdeki çalışma koşullarından haberdar olmaya başlaması örgütün kültürünün çalışanlara yönelik içeriklere sahip olma zorunluluğunu da beraberinde getirmiştir. Örgüt kültürünün çalışanları destekleyici yapıda olması, çalışanlar arasında iyi bir iletişim ortamının sağlanması, ödüllendirme sisteminin yeterli olması, örgüt bünyesindeki çalışanların bağlılıkları açısından önemli bir faktör olabilmektedir. Bu araştırma kapsamında örgüt kültürünün örgütsel bağlılığa etkisinin tespit edilmesi amaçlanmaktadır. Araştırmada sağlık sektörü açısından bir alan araştırması gerçekleştirilmektedir.

Araştırma sonucunda elde edilecek bulgular; sağlık sektöründe çalışan kayıplarının önlenmesi için örgütün kuracağı destek ve iletişim ortamının ve ödüllendirme sisteminin faydalarının görünür olmasını sağlayabilecektir. Söz konusu faydalar incelenirken araştırmanın bazı kısıtlarının da göz ardı edilmemesi gerekmektedir. Bu kısıtlar; araştırmanın sağlık sektörünü kapsaması, araştırmada veri toplama tekniği olarak anket formlarının kullanılmasıdır. Araştırmanın ilk bölümünde araştırmanın kavramsal çerçevesi sunulmaktadır. Araştırmanın kavramsal çerçevesi; örgüt kültürü, örgütsel bağlllık ve kavramlar arası ilişkileri kapsamaktadır. Araştırmanın ikinci bölümünde araştırmanın metodu hakkında bilgiler sunulmaktadır. Araştırmanın metodu bölümü; araştırmanın amacı ve önemi, araştırmanın örneklemi, veri 
toplama tekniği ve modelinden oluşmaktadır. Araştırmanın üçüncü bölümünde ise verilerin analizi sonucunda elde edilen bulgular sunulmaktadır. Son bölümde ise çalışmanın sonucu, elde edilen bulguların tartışılması ve öneriler yer almaktadır.

\section{Araştırmanın Kavramsal Çerçevesi}

Araştırma kapsamında iki ana konu üzerinde durulmaktadır. Bunlardan ilki örgüt kültürüdür. Alanyazında birçok farklı çerçeveden incelenmekle birlikte, çalışma kapsamında örgüt kültürü iletişim ve destek ile ödüllendirme açısından incelenmektedir. Çalışmada incelenen diğer konu olan örgütsel bağlılık ise alanyazında yaygın olarak duygusal bağlılık, devam bağlılığ1 ve normatif bağlllık boyutları ile incelenmektedir. Söz konusu boyutlar bu araştırma kapsamında da kullanılmaktadır.

\section{Örgüt Kültürï}

Örgüt kültürü, genel bir ifadeyle; çalışanların paylaştığı ortak değer, tarih, normlar, iş yapış biçimlerinin tamamı şeklinde tanımlanabilmektedir. Örgüt kültürü; değerler ve normlar, seremoniler ve törenler, hikâyeler ve mitler, varsayımlar, kahramanlar ve liderler, adetler ve törenler, semboller ve dilden oluşur. Örgüt kültürü; Baskın kültür ve alt kültür olarak ikiye ayrılabilmekteyken (Kantek ve Kurnaz 2018) kavram ile ilgili gelişime bakıldığında, AGIL paradigması (Parsons vd. 1953) olarak adlandırılan modelde 4 alt boyut (uyum, amaca ulaşma, bütünleşme, yasallık kültürü), Harrison ve Handy Modelinde (Harrison 1972; Handy 1985) 4 alt boyut (güç, rol, görev, birey odaklı örgüt kültürü), Miles ve Snow (1978) modelinde 4 alt boyut (geliştirici, koruyucu, analizci, tepki verici kültür), Ouchi (1981) Ouchi Z Teorisi modelinde 3 tip örgüt (Amerikan tipi, Japon tipi, karma örgüt), Deal ve Kennedy (1982) modelinde 4 alt boyut (sert adam-maço, çok çalış-sert oyna, şirket üzerine iddiaya gir, süreç kültürü), Kets de Vries ve Miller (1986) modelinde 5 alt boyut (paranoid, çekinik, karizmatik, bürokratik, politik kültür), Pheysey (1993) modelinde 4 alt boyut (güç, rol, başarı, destek kültürü), Cameron ve Quinn'in (1999) Rekabetçi Değerler Modelinde 4 alt boyut (klan, adhokrasi, hiyerarşi, Pazar kültürü) yer almaktadır (Yılmaz vd., 2020). Örgüt kültürü, 
örgütte iş süreçlerinin nasıl yürüdügünü ve diğer örgütlerdeki iş yapış biçimlerinden nasıl ayrıldığını gösteren davranışları içeren, bir örgütü diğerlerinden ayıran en önemli unsurlardan birisidir. (Yılmaz, 2019)

Çalışmada örgüt kültürünün iletişim ve destek kültürü, ödüllendirme alt boyutlarının sağlık çalışanlarının örgütsel bağlılığıyla ilişkisi araştırılmıştır. İletişimin örgüt içinde etkin olarak kullanılmasıyla çalışanlar, örgütteki işleyişten haberdar edilmekte ve kararlara katılımlarının sağlanmasıyla çalışanlarda örgüte karşı duyulan aidiyet duygusu ve motivasyonun arttırılması sağlanabilmektedir. Bu sayede çalıştığı örgütü kendine ait bir yer gibi görmekte ve onu sahiplenmeye başlamaktadır (Aydın vd. 2016). Dürüst ve açık iletişime bağlı olarak, insan ilişkileri ve güven ilişkilerine dayalı destek kültürü, örgüt üyeleri arasındaki karşılıklı ilişki ve bağlılık ile gelişmektedir (Koşar ve Çalık, 2011). Bir diğer örgüt kültürü alt boyutu olan ödüllendirmenin de önemi büyüktür. Ücret dışı yan gelirler, statüde ilerleme, tanınma, terfi ya da daha esnek denetleme gibi ödüller personelin bağlılığını arttırmada etkili olmaktadır (Aydın vd. 2016).

\section{Örgütsel Bă̆lılık}

Örgütsel bağlılık, en genel hali ile iş görenin hizmet ettiği örgüte, örgütün amaç ve değerlerine karşı duymuş olduğu etkili bağlılık olarak tanımlanabilir. Örgütsel bağlılık iş görenin örgüt ile kurmuş olduğu duygusal ve psikolojik ilişkileri içermesi bakımından önem arz etmektedir. Örgütsel bağlılık demografik (yaş, cinsiyet, medeni durum, kurumda çalışma süresi vb.), psikolojik (çatısma, çaresizlik vb.), örgütsel (örgüt kültürü, örgüt iklimi, algılanan destek vb.) birçok farklı unsurdan etkilenmektedir (Özata, 2015). İlgili alanyazında, Meyer ve Allen (1991) tarafından oluşturulmuş olan üç alt boyut (duygusal, devam ve normatif bağllık) uzun zaman örgütsel bağlılık çalışmalarının merkezinde yer almıştır. Çalışanların örgütlerinin değer ve amaçlarını benimsedikleri için örgütte kalma isteği ve duygusal olarak örgüte bağlı olmak duygusal bağlllık; işletmeden ayrılmanın maliyetleri sebebiyle bir zorunluluk olarak işletmeye devam etmesi devam bağlılığı; ahlaki bir görev duygusuyla ve işletmeden ayrılmama gerektiğine inandıkları için kendilerini örgüte bağlı hissetmeleri ise normatif bağlllık olarak ifade edilmektedir. Örgütsel bağlı̆̆ın boyutlarının arkasındaki gerekçeler şu şekildedir; çalışanın 
bağlllığ istemesi (duygusal bağllık), çalışanın bağl1lık zorunda olması (devam bağlllı̆̆ı) ve çalışanın bağl1lı̆̆ 1 doğru bulması (normatif bağlılık)'dır (Tatll, 2014; Arbak ve Kesken, 2005). Örgütsel bağlllıkla ilişkilendirilen tutumsal yaklaşıma göre (Mowday vd. 1979) örgütsel bağlllık; bireyin örgütün değerleri ile olan özdeşleşme derecesi olarak tanımlanmaktadır. Bu araştırma kapsamında inceleneceği üzere, çalışanların örgütün değerleri ile uyumlaşmaları onların örgütlerine olan bağlılıklarını arttırabilmektedir.

\section{Kavramlar Arası İlişkiler ve Hipotez Geliştirme}

Erdem (2007) örgüt kültürü tipleri ile örgütsel bağlllık arasındaki ilişkileri Elazığ il merkezinde yer alan hastanelerde görev yapan 256 çalışan üzerinde yaptığı araştırması ile incelemiştir. Çalışma neticesinde, örgüt kültürünün alt boyutlarından olan klan kültürünün çalışanların örgütsel bağlılıklarını en çok etkileyen boyut olduğu, pazar kültürü ile örgütsel bağlllık arasında ise negatif ilişki bulunduğu saptanmıştır.

Widyaningrum (2012) İbnu Sina Hastanesi Gresik yönetiminde örgütsel kültür ve becerinin örgütsel bağlllık ve sağlık hizmeti çalışanlarının performansı üzerindeki etkisini incelemeyi ve analiz etmeyi amaçlamıştır. Çalışmanın örneklemi tıbbi hizmetler çalışanlarından (doktorlar, ebeler ve hemşireler) oluşan 175 katılımcıdır. AMOS yapısal eşitlik modellemesinin kullanıldığı çalışmanın bulguları örgütsel kültür ve örgütsel bağlılık ilişkisi en büyük önem düzeyine sahipken, yetenek ve çalışan performansı ilişkisinin en zayıf önem düzeyine sahip olduğunu göstermiştir.

Akyürek vd. (2013) sağlik çalışanlarında örgütsel kültür ve alt kültürün örgütsel bağlılığa etkisini araştırdıkları çalışmalarında örgüt kültürünü (bürokratik, destekleyici ve yenilikçi) üç boyut altında ele almışlardır. Wallach tarafından geliştirilen Örgüt Kültürü İndeksi ve Porter'ın Örgütsel Bağlllık Ölçeği olmak üzere iki bolümden oluşan ölçek Ankara ilindeki 93 sağlık çalışanı üzerine uygulanmıştır. Çalışma bulgularına göre, örgütsel kültür ve örgütsel bağlllık arasında pozitif ilişkinin var olduğu, örgütsel alt kültürlerin örgütsel bağlılığı \% 34 oranında açıkladığı belirlenmiştir.

Aydın vd. (2016) örgüt kültürünün ödül, iletişim ve davranışsal güçlendirme alt boyutlarının hastane çalışanlarının örgütsel bağlıllı̆ına etkisini araştırmak amacıyla 250 sağlık çalışanından anket tekniği ile veri toplamışlardır. 
Çalışma neticesinde örgüt kültürünün alt boyutları ile örgütsel bağlllık boyutları arasında pozitif yönde ilişki bulunmuştur.

Özata (2015) hastanelerde görev yapan sağlık çalışanlarının örgütsel bağlılık düzeylerinin belirlenmesi amaçlayan çalışmasını Konya'da faaliyet gösteren üç farklı hastanede görev 173 personel ile gerçekleştirmiştir. Araştırmada özel hastane personellerinin örgütsel bağlllık düzeyinin devlet hastanesinde görev yapanlardan daha düşük seviyede olduğu ve örgütsel bağlllık ile yaş arasında negatif ve anlamlı bir ilişki saptanmıştır.

Yıldız (2017) sağlık çalışanlarının örgütsel bağlılık algıları ile örgüt kültürü arasındaki ilişkinin incelenmesi amacıyla İstanbul Üniversitesi İstanbul Tıp Fakültesi Hastanesinde çalışan 250 hemşire üzerinde anket uygulaması yapmıştır. Araştırma bulgularına göre örgüt kültürü ve örgütsel bağlılık arasında ilişki tespit edilmiştir. Ayrıca alt boyutlar açısından duygusal bağlllık ve normatif bağlılık her tipteki örgüt kültürü ile pozitif ilişki barındırırken devam bağlılığı ile Hiyerarşi Tipi Örgüt kültürü algısı arasında negatif ilişki tespit edilmiştir.

Kolancıoğlu ve Karabulut (2018) örgüt kültürünün örgütsel bağlllık üzerindeki etkisini araştırmak amacıyla Kocaeli'ndeki 3 hastaneden kolayda örneklem yoluyla ulaşılan 334 kişi üzerinden, anket formu ile araştırma gerçekleştirmişlerdir. Örgüt kültürünün örgütsel bağlllı̆̆ pozitif yönlü etkilediği sonucuna ulaşmışlardır.

Örgüt kültürü ve örgütsel bağlllık üzerine ilgili alanyazında çok sayıda çalışma olduğu ve bu çalışmalar içerisinde sağlık kuruluşları ile ilgili olanların da bulunduğu (Örn; Chen 2004; Erdem 2007; Widyaningrum 2012, Akyürek vd. 2013; Aydın vd. 2016) görülmektedir. Örgüt kültürü ve örgütsel bağlllık arasında pozitif ilişkinin olduğu (Örn; Chen 2004; Erdem 2007; Kaya 2008; Çavuş ve Gürdoğan 2008; Demir ve Öztürk 2011; Widyaningrum 2012 Akyürek vd. 2013; Aydın vd. 2016; Kolancıŏllu ve Karabulut 2018; Toker vd. 2019) çalışmalar göz önüne alındığında örgüt kültürünün, örgütsel bağlllık üzerinde önemli bir etkisinin olduğu ve buradan yola çıarak yüksek örgütsel bağlılığa sahip olan çalışanların olduğu kurumlarda işten ayrılmaları azaltmak, motivasyonu ve verimliliği arttırmak gibi etkilerinin olması beklenebilir. Söz konusu bakış özellikle 2020 yılının tamamını salgın yılı haline getiren COVID-19 virüsünün etkilerinin sağlık çalışanları üzerinde yarattığ baskı göz önüne alındığında ayrıca önem kazanmaktadır. Özellikle böyle bir kriz döneminde sağlık çalışanlarının örgütsel bağlılığının yüksek olmasının 
verilecek hizmetin kalitesi açısından büyük önem arz ettiği söylenebilir. Bu çıkarımlardan yola çıkılarak araştırmanın hipotezleri şu şekilde oluşturulmuştur;

- H: Örgüt kültürü örgütsel bağhlı̆̆ı olumlu yönde etkilemektedir.

o H1a: İletişim ve destek kültürü duygusal bağl1lığı olumlu yönde etkilemektedir.

o Hı: Ödüllendirme kültürü duygusal bağlllığı olumlu yönde etkilemektedir.

o H1c: İletişim ve destek kültürü normatif bağlılığı olumlu yönde etkilemektedir.

o H1d: Ödüllendirme kültürü normatif bağlılığı olumlu yönde etkilemektedir.

o H1e: İetişim ve destek kültürü devam bağlılığını olumlu yönde etkilemektedir.

o Hıf: Ödüllendirme kültürü devam bağlılığını olumlu yönde etkilemektedir.

\section{Yöntem}

Araştırmanın metodolojisi bölümünde, araştırmanın hangi amaçla gerçekleştirildiği ve elde edilen sonuçların hangi açıdan önemli olduğu, araştırmanın örnekleminin ve örnekleme yöntemi, araştırmada kullanılan veri toplama araçlarının neler olduğu ve son olarak araştırmanın modeli hakkında bilgiler sunulmaktadır.

\section{Araştırmanın Amacı Ve Önemi}

Yerli ve yabancı alanyazın incelendiğinde örgüt kültürü ve örgütsel bağlllık konularında bir çok çalışma olduğu görülmektedir. Örgüt kültürü ve örgütsel bağlılık arasındaki ilişkilerin tespit edilmesini amaçlayan çalışmalara rastlamak mümkündür. Söz konusu araştırmalarda örgüt kültürünün görevsel ve örgütsel (Gülova ve Demirsoy, 2012), sosyalleşme-katılım-ödül, semboller, tarihsel geçmiş, iletişim, tören (Demir ve Öztürk, 2011; Çavuş ve Gürdoğan, 2008) klan eğilimi, gelişme eğilimi, profesyonelizm eğilimi, açılık eğilimi, otorite eğilimi, bürokrasi eğilimi, sonuç eğilimi, informellik eğilimi, itaat eğilimi (Kaya, 2008), kuralcılık, açıklık, klan, destekleyicilik, hiyerarşi ve gelişme eğilimleri (Diker, 2014), destek kültürü, başarı kültürü, bürokratik kültür ve 
görev kültürü (Sezgin, 2010), destekleyici, bürokratik ve yenilikçilik kültürü (Akyürek vd. 2013) gibi şekillerde boyutlarla incelendiği görülmektedir. Ancak bu çalışmalardan farklı olarak bu araştırmada örgüt kültürü iki boyut üzerinden incelenmektedir; iletişim ve destek kültürü ile ödüllendirme kültürü. Araştırmada kullanılan şekli ile örgüt kültürünün örgütsel bağlllık üzerinde nasıl bir etkiye sahip olduğunun tespit edilmesi, çalışan sermayesinden daha uzun süre faydalanmak açısından önemlidir. Örgütlerde iletişimin kültürel bir unsura dönüştürülmesi, çalışanların desteklendiği bir örgüt şekli oluşturulması ve çalışanların içsel açıdan ve maddi olarak ödüllendirilmesi, çalışanların örgüte olan bağlılıklarını güçlendirecek önemli bir unsur olabilecektir. Bu nedenle araştırmanın amacı örgüt kültürünün çalışanların örgütsel bağlılığına etkisinin tespit edilmesi olarak belirlenmiştir. Araştırma sonucunda elde edilecek bulgular; çalışanların örgütlerine olan duygusal, normatif ve devamlılık bağlılıklarında örgütün iletişim ve destek kültürü ile ödüllendirme kültürünün rolünü açıklama açısından önem taşımaktadır. Böylece çalışanların kayıplarının önlenmesi için örgütün kuracağı destek ve iletişim ortamının ve ödüllendirme sisteminin faydalarının görünür olması sağlanabilecektir.

\section{Araştırmanın Örneklemi}

Araştırmanın örneklemi İstanbul ilinde sağlık sektöründe çalışan hemşirelerden oluşmaktadır. Çalışma ile ilgili olarak Beykent Üniversitesi'nden 30.09.2020 tarihinde gerekli etik kurul izni alınmıştır. Örnekleme ulaşabilmek için bir özel bir sağlık kuruluşunda çalışan 400 kişiden 300'üne anket formları verilmiştir. Dağıtılan 300 adet formdan 259 tanesine uygun dönüş alınmıştır. Örneklem belirlemede basit tesadüfi örneklem tekniği kullanılmıştır. Basit tesadüfi örnekleme tekniği Büyüköztürk vd. (2016) tarafından şu şekilde açıklanmaktadır; basit tesadüfi örnekleme, örneklem içerisinde yer alan her bir bireye eşit katılım sağlamakta ve örneklemden elde edilen sonuçların genellenebilirliğine katkı sağlamaktadır. Yani basit tesadüfi örnekleme tekniği temsil gücü bakımından oldukça güçlüdür. Örneklem sayısının belirlenmesinde Hair vd. (2014) tarafindan uygun görülen madde başına örnekleme hesaplaması kullanılmıştır. Hair vd. (2014)'e göre araştırmada kullanılan ölçüm araçlarında yer alan her madde için en az 5 örnekleme ulaşılması gerekmek- 
tedir. Böylece maddeler arası ilişkilerin doğru hesaplanması mümkün olabilmektedir. Söz konusu görüşlerden yola çıkıldığında, araştırma kapsamında kullanılan 30 madde için en az 150 örnekleme ulaşmak gerekmektedir, toplamda 259 örnekleme ulaşılarak söz konusu kısıt sağlanmıştır.

\section{Araştırmanın Veri Toplama Araçları}

Araştırma kapsamında üç bölümden oluşan anket formu kullanılmıştır. Anket formumun ilk kısmında katılımcıların demografik özelliklerinin (yaş, cinsiyet, eğitim, toplam tecrübe, kıdem) tespit edilmesine yönelik 5 adet soru sorulmuştur. Anket formunun ikinci bölümünde örgüt kültürünün temsilen 12 maddeden, 3 ana boyuttan meydana gelen ve Aydın vd. (2016) tarafından oluşturulan ölçüm aracı kullanılmıştır. Örgütsel bağlllığın ölçülmesinde ise Allen ve Meyer (1990) tarafından oluşturulan ölçüm aracı kullanılmıştır. Örgütsel bağlllık ölçeğinin Türkçe formu Wasti (2000), Tatlı (2014), Öngel (2018) tarafından yapılan çalışmalardan elde edilmiştir. Örgütsel bağlllık ölçeği 18 maddeden ve 3 boyuttan meydana gelmektedir. Anket formunda 5'li likert ölçümü kullanılmıştır (1-kesinlikle katılmıyorum, 5-kesinlikle katılıyorum).

\section{Araştırmanın Modeli}

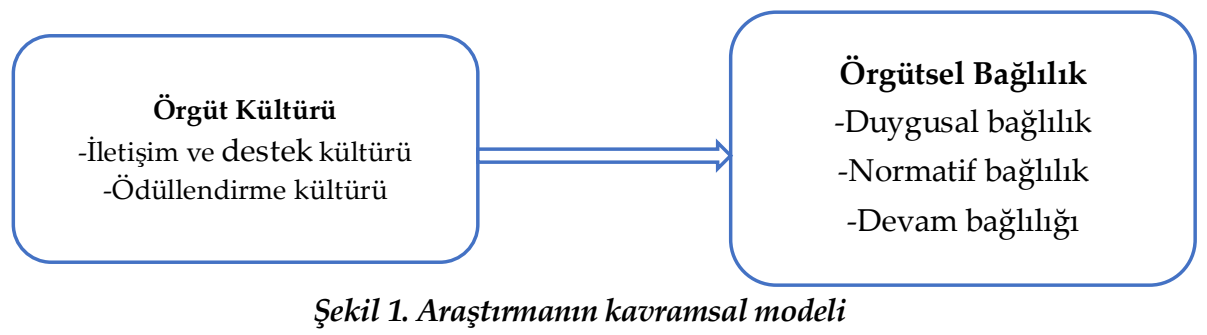

Araştırmanın kavramsal modeli Şekil 1'de yer almaktadır. Şekilde yer alan örgüt kültürü ve alt boyutları (iletişim ve destek kültürü ile ödüllendirme kültürü) araştırmanın bağımsız değişkenini, örgütsel bağlılık ise bağımlı değişkenini oluşturmaktadır.

\section{Araştırmanın Bulguları}

Araştırmanın bu aşamasında faktör analizi, güvenilirlik analizi, tanımlayıcı istatistikler, korelasyon analizi ve regresyon analizi sonuçları hakkındaki bulgular ve yorumlamalara yer verilmektedir. 


\section{Faktör Analizi Sonuçlan}

Araştırmada kullanılan ölçüm araçlarının geçerliliğini tespit edebilmek için yapılan faktör analizi sonuçları bu bölümde yer almaktadır. Faktör analizi sonucunda elde edilen KMO (Kaiser-Meyer-Olkin Örneklem Yeterliliği Ölçümü) değeri, Bartlett's Küresellik Testi sonucu, açıklanan toplam varyans ve bileşen matrisi (varimax rotasyonu) hakkındaki bulgular sunulmaktadır. Söz konusu bulguların değerlendirilmesinde kullanılan sınır değerlerinde Hair (2014) tarafından sunulan ve alanyazında yaygın olarak kullanılan değerler (KMO; 0,600 ve üzeri, Bartlett's testi; $\mathrm{p}<0,05$, açılanan toplam varyans; 0,60 ve üzeri, faktöre yükleme; 0,40 ve üzeri) esas alınmaktadır.

Tablo 3.1. Örgüt kültürü ölçeğinin faktör analizi sonuçlar

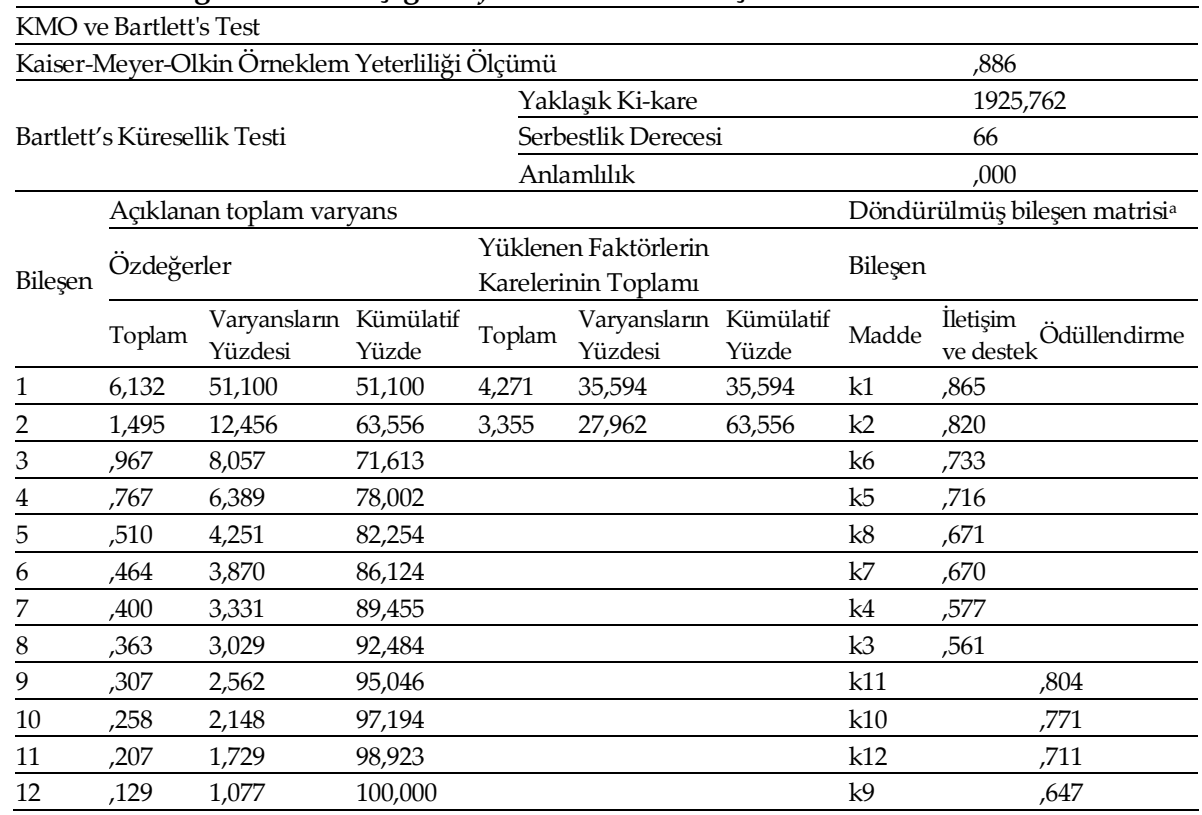

Örgüt kültürü ölçeğinin faktör analizi sonuçları Tablo 3.1'de yer almaktadır. Örgüt kültürü ölçeğinin KMO değeri 0,886, Bartlett's testi sonucu 0,000< $\mathrm{p}<0,05$, açıklanan toplam varyansı \%63,55 olarak tespit edilmiştir. Örgüt kültürü ölçeğinin iletişim ve destek kültürü ile ödüllendirme kültürü olarak iki faktöre ayrıldığı, faktörleşmede hiçbir maddenin yükleme değerinin 0,40 de- 
ğerinden düşük olmadığ1 görülmektedir. Ayrıca ölçeğin iki faktöründeki özdeğerlerin $>1,00$ olduğu, iletişim ve destek kültürü boyutunun açılanan varyansının \%35,59, ödüllendirme kültürü boyutunun açıklanan varyansının ise \%27,96 olduğu sonucuna ulaşılmıştır. Ölçek içerisindeki hiçbir soru araştırma kapsamı dışında bırakılmamıştır. Örgüt kültürü ölçeğinin faktör analizi sonuçları incelendiğinde ölçeğin yeterli düzeyde değerlere sahip olduğunu ifade etmek mümkündür.

Tablo 3.2. Örgütsel bağlılık ölçeğinin faktör analizi sonuçlarn

\begin{tabular}{|c|c|c|c|c|c|c|c|c|c|c|}
\hline \multicolumn{11}{|c|}{ KMO ve Bartlett's Test } \\
\hline \multicolumn{7}{|c|}{ Kaiser-Meyer-Olkin Örneklem Yeterliliği Ölçümü } & \multicolumn{4}{|c|}{846} \\
\hline \multirow{3}{*}{\multicolumn{4}{|c|}{ Bartlett's Küresellik Testi }} & \multicolumn{3}{|c|}{ Yaklaşık Ki-kare } & \multicolumn{4}{|c|}{2040,204} \\
\hline & & & & \multicolumn{3}{|c|}{ Serbestlik Derecesi } & \multicolumn{4}{|c|}{120} \\
\hline & & & & \multicolumn{3}{|c|}{ Anlamlılık } & \multicolumn{4}{|c|}{, 000 } \\
\hline & \multicolumn{6}{|c|}{ Açıklanan toplam varyans } & \multicolumn{4}{|c|}{ Döndürülmüş bileşen matrisia } \\
\hline \multirow{2}{*}{ Bileşen } & \multicolumn{3}{|c|}{ Özdeğerler } & \multicolumn{3}{|c|}{$\begin{array}{l}\text { Yüklenen Faktörlerin } \\
\text { Karelerinin Toplamı }\end{array}$} & \multicolumn{4}{|l|}{ Bileşen } \\
\hline & Toplam & Varyansların Kümülatif & $\begin{array}{l}\text { Kümülatif } \\
\text { Yüzde }\end{array}$ & Toplam & \multicolumn{2}{|c|}{ Varyansların Kümülatif } & Madde & $\begin{array}{l}\text { Duygusal } \\
\text { bağlllık }\end{array}$ & $\begin{array}{l}\text { Normatif } \\
\text { bağllık }\end{array}$ & $\begin{array}{l}\text { Devam } \\
\text { bağlllığı }\end{array}$ \\
\hline 1 & 5,624 & 35,147 & 35,147 & 4,021 & 25,131 & 25,131 & b3 & 876 & & \\
\hline 2 & 2,655 & 16,596 & 51,743 & 3,203 & 20,018 & 45,149 & $\mathrm{~b} 4$ & 872 & & \\
\hline 3 & 1,536 & 9,599 & 61,342 & 2,591 & 16,193 & 61,342 & b5 & 834 & & \\
\hline 4 & ,908 & 5,678 & 67,019 & & & & $\mathrm{~b} 2$ & ,741 & & \\
\hline 5 & 826 & 5,164 & 72,184 & & & & $\mathrm{~b} 6$ & ,720 & & \\
\hline 6 & ,728 & 4,548 & 76,732 & & & & b1 & 606 & & \\
\hline 7 &, 597 & 3,728 & 80,460 & & & & b16 & & ,825 & \\
\hline 8 &, 537 & 3,353 & 83,813 & & & & b15 & & 804 & \\
\hline 9 & 473 & 2,958 & 86,772 & & & & b17 & & ,688 & \\
\hline 10 &, 444 & 2,774 & 89,546 & & & & b14 & & ,682 & \\
\hline 11 & 401 & 2,506 & 92,052 & & & & b18 & & 626 & \\
\hline 12 & ,338 & 2,112 & 94,164 & & & & b10 & & & ,780 \\
\hline 13 & 300 & 1,878 & 96,042 & & & & b9 & & & 757 \\
\hline 14 & 274 & 1,710 & 97,752 & & & & b12 & & & ,750 \\
\hline 15 & , 186 & 1,164 & 98,916 & & & & $\mathrm{~b} 8$ & & & ,743 \\
\hline 16 & ,173 & 1,084 & 100,000 & & & & b7 & & &, 515 \\
\hline
\end{tabular}

Örgütsel bağl1lık ölçeğinin faktör analizi sonuçları Tablo 3.2' de yer almaktadır. Örgütsel bağlllık ölçeğinin KMO değeri 0,846, Bartlett's testi sonucu $0,000<\mathrm{p}<0,05$, açıklanan toplam varyansı $\% 61,34$ olarak tespit edilmiştir. Ölçeğin duygusal bağlılık, normatif bağlılık ve devam bağlılığı olmak üzere üç boyuta ayrıldığı görülmektedir. Faktörlere ayırma esnasında hiçbir maddenin yükleme değerinin 0,40 değerinden düşük olmadığı görülmektedir. Ayrıca ölçeğin üç faktöründeki özdeğerlerinin $>1,00$ olduğu görülmektedir. Faktörlerin açılanan varyansları incelendiğinde; duygusal bağlllık boyutu 
\%25,13, normatif bağlılık boyutu \%20,01 ve devam bağl1lığ1 boyutu \% 16,19 'dur. Boyutların açıklama düzeylerinin birbirlerine yakın olduğu görülmektedir. Ölçek içerisindeki iki madde (b11: eğer bu kuruma kendimden çok fazla şey katmamış olsaydım, başka yerde çalışmayı göz önünde bulundurabilirdim, b13: menfaatime olsa bile, kurumumdan ayrılmanın doğru olmad1ğını düşünüyorum) araştırma kapsamı dışında bırakılmıştır. Maddelerin uygun dağılım sağlamaması, faktör değerlerinin düşük olması gibi unsurlar göz önüne alınarak kapsam dışında bırakılmıştır.

\section{Güvenilirlik Sonuçları}

Araştırmada kullanılan ölçüm araçlarının yeterli düzeyde güvenilirlik sağladığını tespit edebilmek için güvenilirlik analizi yapılmıştır. Güvenilirlik katsayısı olarak Cronbach's Alpha katsayısı kullanılmıştır. Örgüt kültürü ve örgütsel bağlılık ölçekleri ile ilgili güvenilirlik analizi sonuçları aşağıda yer almaktadır.

Tablo 3.3. Örgüt kültürü̈ ölçeğinin güvenilirlik analizi sonuçlan

\begin{tabular}{|c|c|c|c|}
\hline & Madde Silindiğinde Cronbach's Alpha Katsayısı & Cronbach's Alpha & Madde Sayısı \\
\hline $\mathrm{k} 1$ & ,905 & \multirow{12}{*}{,- 909} & \multirow{12}{*}{12} \\
\hline $\mathrm{k} 2$ & ,906 & & \\
\hline $\mathrm{k} 3$ & 901 & & \\
\hline $\mathrm{k} 4$ & 899 & & \\
\hline $\mathrm{k} 5$ & 895 & & \\
\hline $\mathrm{k} 6$ & 896 & & \\
\hline $\mathrm{k} 7$ & 899 & & \\
\hline $\mathrm{k} 8$ & 899 & & \\
\hline $\mathrm{k} 9$ & 901 & & \\
\hline $\mathrm{k} 10$ & ,912 & & \\
\hline $\mathrm{k} 11$ & ,905 & & \\
\hline $\mathrm{k} 12$ & 903 & & \\
\hline
\end{tabular}

Tablo 3.3'te örgüt kültürü ölçeğinin güvenilirlik analizi sonuçları yer almaktadır. Örgüt kültürü ölçeğinin Cronbach's Alpha katsayı 0,909 olarak tespit edilirken ölçekte 12 madde yer almıştır. K10 olarak kodlanan maddenin silinmesi durumunda Cronbach's Alpha katsayısının 0,912 olacağ1 görülmektedir. Ancak elde edilecek olan düşüş çok düşük düzeyde olması ve ölçüm aracının çok yüksek bir güvenilirlik katsayısına sahip olmasından dolayı K10 olarak kodlanan madde araştırma kapsamında tutulmuştur. Örgüt kültürü ölçeğinin araştırma kapsamında kullanılmasının uygun olduğunu ifade etmek mümkündür. 
Tablo 3.4. Örgütsel bağhllı ölçeğinin güvenilirlik analizi sonuçlan

\begin{tabular}{|c|c|c|c|}
\hline & Madde Silindiğinde Cronbach's Alpha Katsayisı & Cronbach's Alpha & Madde Sayııı \\
\hline b1 &, 830 & & \multirow{16}{*}{16} \\
\hline b2 &, 832 & & \\
\hline b3 & 831 & & \\
\hline 4 & .824 & & \\
\hline 35 & 826 & & \\
\hline$\overline{b 6}$ & .827 & & \\
\hline 87 & .842 & & \\
\hline $\mathrm{b} 8$ & 847 & & \\
\hline b9 & .852 & & \\
\hline b10 &, 850 & & \\
\hline 12 & 849 & & \\
\hline b14 & 836 & & \\
\hline b15 & 828 & & \\
\hline b16 & .830 & & \\
\hline b17 & 829 & & \\
\hline b18 & 828 & & \\
\hline
\end{tabular}

Örgütsel bağlllık ölçeğinin güvenilirlik analizi ile ilgili bulgular Tablo 3.4'te yer almaktadır. Örgütsel bağlılık ölçeğinin Cronbach's Alpha katsayısı 0,844 olarak tespit edilmiştir. Ayrıca ölçüm aracında 16 madde yer almıştır. Ölçüm aracında yer alan B8, B9, B10 ve B12 maddelerinin 0,844 değerinden yukarıda olduğu görülmektedir. Ancak ölçeğin hâlihazırda çok yüksek düzeyde güvenirlik katsayısına sahip olması ve söz konusu maddeler ölçekten çıkarıldığında güvenilirlik katsayısında önemli değişmelere yol açmayacağından söz konusu maddeler araştırma kapsamında tutulmuştur. Faktör analizi esnasında araştırmadan çıarılan B11 ve B13 kodlu maddeler ise güvenilirlik analizine dâhil edilmemiştir.

\section{Tanımlayıcı istatistikler}

Araştırmada yer alan katılımcıların özellikleri ve katılımcıların araştırmada kullanılan ölçüm araçlarındaki maddelere vermiş oldukları yanıtlar hakkındaki tanımlayıcı istatistikler bu bölümde sunulmuştur. 
Tablo 3.5. Katılımcların demografik özellikleri

\begin{tabular}{|c|c|c|c|c|c|c|c|}
\hline Değişken & Özellik & Sayı & $\%$ & Değişken & Özellik & Sayı & $\%$ \\
\hline \multirow{3}{*}{ Cinsiyet } & Erkek & 37 & 14,3 & \multirow{6}{*}{-Yaş } & 24 ve altı & 72 & 27,8 \\
\hline & Kadın & 222 & 85,7 & & 25-29 yaş & 79 & 30,5 \\
\hline & Toplam & 259 & 100,0 & & 30-34 yaş & 38 & 14,7 \\
\hline \multirow{5}{*}{$\begin{array}{l}\text { Toplam } \\
\text { tecrübe }\end{array}$} & 3 yıl ve altı & 115 & 44,4 & & $35-39$ yaş & 25 & 9,7 \\
\hline & $4-7 \mathrm{yll}$ & 54 & 20,8 & & 40 ve üzeri & 45 & 17,4 \\
\hline & $8-11 \mathrm{yll}$ & 30 & 11,6 & & Toplam & 259 & 100,0 \\
\hline & 12 yıl ve üzeri & & 23,2 & \multirow{4}{*}{$\begin{array}{l}\text { Eğitim } \\
\text { rumu }\end{array}$} & Lise & 34 & 13,1 \\
\hline & Toplam & 259 & 100,0 & & du-Önlisans & 193 & 74,5 \\
\hline \multirow{4}{*}{ Kıdem } & $0-2$ yil & 109 & 42,1 & & Lisans & 32 & 12,4 \\
\hline & $3-5 \mathrm{yll}$ & 75 & 29,0 & & Toplam & 259 & 100,0 \\
\hline & 6 yıl ve üzeri & 75 & 29,0 & \multirow{2}{*}{-Kişi: 259} & & & \\
\hline & Toplam & 259 & 100,0 & & & & \\
\hline
\end{tabular}

Araştırma kapsamında yer alan katılımcların demografik özellikleri ile ilgili bulgular Tablo 3.5'te yer almaktadır. Katılımcların \%14,3'ü erkeklerden $\% 85,7$ 'si kadınlardan oluşmaktadır. Katılımcıların \%44,4'ü 3 yıl ve altında, \%20,8'i 4-7 yıl arasında, \%11,6'sı 8-11 yıl arasında, \%23,2'si ise 12 yıl ve üzerinde toplam tecrübeye sahiptir. Katılımcıların \%42,1'i 2 yıl ve altında, \%29'u 3-5 yıl arasında, \%29'u ise 6 yıl ve üzerinde bir süredir aynı kurumda çalışmaktadır. Katılımcıların yaş dağılımı incelendiğinde; $\% 27,8^{\prime}$ inin 24 yaş ve altında, \%30,5'inin 25-29 yaş aralığında, \%14,7'sinin 30-34 yaş aralığında, $\% 9,7^{\prime} \operatorname{sinin} 35-39$ yaş aralığında, \%17,4'ünün ise 40 yaş ve üzerinde olduğu görülmektedir. Katılımcıların eğitim düzeyleri incelendiğinde; \%13,1'inin lise, \%74,5' inin Önlisans, \%12,4'ünün ise lisans düzeyinde eğitim aldıkları görülmektedir.

Tablo 3.6. Tanımlayıcı istatistikler

\begin{tabular}{llllll}
\hline Değişken & Ortalama & Std. Sapma & Değişken & Ortalama & $\begin{array}{l}\text { Std. } \\
\text { Sapma }\end{array}$ \\
\hline Duygusal bağllık & 2,8964 & 0,91009 & $\begin{array}{l}\text { Ödüllendirme } \\
\text { kültürü }\end{array}$ & 2,5483 & 0,87221 \\
\hline Normatif bağlllık & 2,8463 & 0,86069 & Örgüt kültürü & 3,0582 & 0,74656 \\
\hline Devam bağllı̆̆ı & 3,2232 & 0,79011 & Örgütsel bağllık & 2,9829 & 0,60872 \\
\hline İetişim ve destek kültürü & 3,3132 & 0,80208 & & & \\
\hline
\end{tabular}

Araştırmada yer alan katılımclların örgüt kültürü ve örgütsel bağlllık ile ilgili görüşlerine ait tanımlayıcı istatistikler Tablo 3.6' da yer almaktadır. Katılımcılardan alınan yanıtlar 5'li Likert ölçümle sağlandığından yorumlamalar 1 ila 5 aralığında yapılmaktadır. Katılımcıların duygusal bağlılık, devam bağlılığ düzeylerinin kararsızlık seviyesinde olduğu görülmektedir. Bunun ya- 
nında örgütün iletişim ve destek kültürü ile ilgili algılar kararsızlık seviyesinin biraz üzerindedir. Örgütün ödüllendirme kültürü ile ilgili katılımcı algısı ise olumsuz düzeydedir. Genel ölçekler açısından yorumlandığında ise; çalışanların hem örgüt kültürü hem de örgütsel bağlılık düzeylerinin kararsızlık seviyesinde olduğunu ifade etmek mümkündür.

\section{Korelasyon Ve Regresyon Analizi Sonuçları}

Değişkenler arasındaki ilişkilerin belirlenebilmesi için korelasyon analizi kullanılmaktadır. Bağımsız değişkenlerin bağımlı değişkeni açıklama düzeyi ise regresyon analizi ile belirlenmektedir. Korelasyon analizinin ve regresyon analizinin öne çıkan varsayımı normal dağılımdır (Hair vd. 2014). Bu araştırmada verilerin normal dağılım varsayımının test edilmesi sonucunda normal dağılımın sağlanmadığı görülmüştür. Bunun yanında normal dağılımın varsayılmasında Tabachnick ve Fidell (2013), George ve Mallery (2010) ve Hair vd. (2014) tarafından çarpıklık ve basıklık değerlerinin kullanılması önerilmektedir. Bu araştırmacıların önerilerinden hareketle çarpıklık ve basıklık değerleri incelenmiştir. Söz konusu değerlerin -1,5 ila 1,5 arasında yer aldığı görülmüştür. Çarpıklık ve basıklık değerlerinin uygun aralıkta olması ile Pearson korelasyon ve doğrusal regresyon analizlerinin yapılmasına karar verilmiştir. Korelasyon ve regresyon analizi sonuçları bu bölümde yer almaktadir.

Tablo 3.7. Korelasyon analizi sonuçlan

\begin{tabular}{|c|c|c|c|c|c|}
\hline & & $\begin{array}{l}\text { Duygusal } \\
\text { bağllilık }\end{array}$ & $\begin{array}{l}\text { Normatif } \\
\text { bağlılık }\end{array}$ & $\begin{array}{l}\text { Devam } \\
\text { bağ } \operatorname{lll}_{\breve{g}}{ }_{1}\end{array}$ & $\begin{array}{l}\text { Örgütsel bağ- } \\
\text { lılık }\end{array}$ \\
\hline \multirow{3}{*}{ İletişim ve destek kültürü } & Pearson Korelasyon & $420^{* *}$ & $317^{* \prime \prime}$ & $164^{* *}$ & $443^{*+1}$ \\
\hline & Anlamlılık (2-tailed) & 000 & 000 & ,008 & 000 \\
\hline & $\mathrm{N}$ & 259 & 259 & 259 & 259 \\
\hline \multirow{3}{*}{ Ödüllendirme kültürü } & Pearson Korelasyon & $478^{* *}$ & $375 *$ & 054 & $456^{* *}$ \\
\hline & Anlamllık (2-tailed) &, 000 &, 000 & ,386 &, 000 \\
\hline & $\mathrm{N}$ & 259 & 259 & 259 & 259 \\
\hline \multirow{3}{*}{ Örgüt kültürü } & Pearson Korelasyon & $487^{\prime \prime \prime}$ & $373^{* *}$ &, $139^{*}$ &, $494^{* *}$ \\
\hline & Anlamllık (2-tailed) & 000 & 000 & ,026 & 000 \\
\hline & $\mathrm{N}$ & 259 & 259 & 259 & 259 \\
\hline
\end{tabular}

Değişkenler arasındaki ilişkilerin test edilmesi amacıyla yapılan korelasyon analizi sonuçları Tablo 3.7'de yer almaktadır. Korelasyon analizi sonucunda; örgüt kültürü ile örgütsel bağlllık arasında orta düzeyde, pozitif 
yönlü ve istatistiki olarak $(p<0,05)$ anlamlı ilişki olduğu tespit edilmiştir. Örgütsel bağlllık ile örgüt kültürünün iletişim ve destek kültürü ve ödüllendirme kültürü arasında ise orta düzeyde, pozitif yönlü ve istatistiki $(p<0,05)$ olarak anlamlı ilişkiler tespit edilmiştir. Bunun yanında alt boyutlar arasında da bazı anlamlı ilişkiler tespit edilmiştir; iletişim ve destek kültürü ile duygusal bağlllık arasında orta düzeyde, pozitif yönlü ve istatistiki olarak $(\mathrm{p}<0,05)$ anlamlı ilişki olduğu görülmektedir. İletişim ve destek kültürü ile normatif bağlllık arasında düşük düzeyde, iletişim ve destek kültürü ile devam bağlllığı arasında çok düşük düzeyde pozitif yönde ve istatistiki olarak $(\mathrm{p}<0,05)$ anlamlı ilişkiler tespit edilmiştir. Ödüllendirme kültürü ile duygusal bağlllık arasında orta düzeyde, ödüllendirme kültürü ile normatif bağlllık arasında düşük düzeyde, pozitif yönde ve istatistiki olarak $(p<0,05)$ anlamlı ilişkiler olduğu tespit edilmiştir. Bunun yanında ödüllendirme kültürü ile devam bağlılığı arasında anlamlı bir ilişki tespit edilmemiştir. Son olarak örgüt kültürü ile duygusal bağlılık arasında orta düzeyde, örgüt kültürü ile normatif bağlllık arasında düşük düzeyde; örgüt kültürü ile devam bağlılığı arasında çok düşük düzeyde, pozitif yönde ve istatistiki olarak anlamlı ilişkiler olduğu sonucuna ulaşılmıştır. Korelasyon analizi sonucunda elde edilen ilişkilerin anlamlılıklarına göre regresyon analizi yapılmıştır. Regresyon analizi sonuçları aşağıda yer almaktadır.

Tablo 3.8. Örgüt kültürü boyutlarınn duygusal bağhllı̆̆a etkisi

\begin{tabular}{|c|c|c|c|c|c|c|c|c|c|c|c|c|}
\hline Mode & zzetib & & & & & Anova & & Katsayıla & & & & \\
\hline $\begin{array}{l}\bar{\nabla} \\
\bar{z}\end{array}$ & $\simeq$ & $\approx$ & 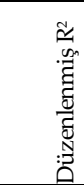 & 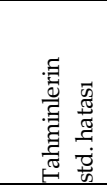 & 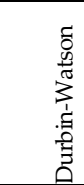 & एᄄ & 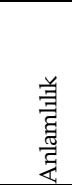 & & 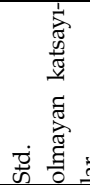 & & 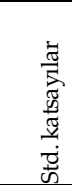 & $\begin{array}{l}\text { 弟 } \\
\text { 就 } \\
\text { 娄 }\end{array}$ \\
\hline 1 &, $506^{\mathrm{a}}$ & ,256 & ,251 & 78785 & 1,706 & 44,137 &, $000^{\mathrm{b}}$ & $\mathrm{B}$ & & Std. ha & Beta & \\
\hline b. Bağ & nlı değ & işken: I & iygusa & ğllılk & & $\underline{\text { Sabit }}$ & & & 1,175 & 210 & & ,000 \\
\hline a. Tah & in de & işken & bit), & & & İletişim & ve des & stek külttür & $\ddot{\mathrm{u}}, 236$ & ,077 & ,208 & ,002 \\
\hline ödülle & dirme & kültüri & iletişim & destek k & & Ödülle & ndirme & e kültürü &, 369 &, 070 &, 353 & ,000 \\
\hline
\end{tabular}

Örgüt kültürünün iletişim ve destek kültürü boyutu ve ödüllendirme kültürü boyutunun, örgütsel bağl1lığın duygusal bağlılık boyutu üzerindeki etkisini tespit edebilmek için yapılan regresyon analizi sonuçları Tablo 3.8' de yer almaktadır. Bulgulara doğrultusunda ödüllendirme kültürü ile iletişim ve destek kültürünün duygusal bağlllığa etkisinin \%25,1 (düzeltilmiş $\mathrm{R}^{2}$ : 
0,251) olduğu görülmektedir. Regresyon modelinin anlamlılığının test edilmesi için incelenen Anova değeri ise $\mathrm{p}<0,05$ düzeyinde istatistiki olarak anlamlı bulunmuştur. Bunun yanında iletişim ve destek kültürü değişkeninin duygusal bağlılığı arttırma düzeyi 0,208 (Std. Beta), ödüllendirme kültürünün duygusal bağl1lı̆̆ arttırma düzeyi ise 0,353 (Std. Beta) olarak tespit edilmiş ve elde edilen açıklama düzeylerinin istatistiki olarak anlamlı olduğu $(p<0,05)$ tespit edilmiştir. Değişkenler arasındaki otokorelasyonun varlığının kontrol edilmesi için kullanılan Durbin-Watson değerinin 1,706<3,000 düzeyinde olduğu, yani değişkenler arasında otokorelasyon olmadığı sonucuna ulaşılmıştır. Elde edilen bulgular genel olarak yorumlanacak olursa; örgüt içinde uygun iletişim kültürünün, çalışanları destekleyici bir kültürün ve uygun ödüllendirme kültürünün olması, çalışanların bulundukları örgütle duygusal açıdan bağ kurmalarını sağlamaktadır. Böylece çalışanlar örgütlerine duygusal bağlllık duyabileceklerdir. Bunun yanında örgütün ödüllendirme kültürü duygusal bağlıllğın artmasını iletişim ve destek kültürüne göre daha yüksek düzeyde etkilemektedir. Elde edilen bulgular doğrultusunda " $\mathrm{H}_{1 a}$ ve Hib" hipotezleri desteklenmiştir.

Tablo 3.9. Örgüt kültürü boyutlarnın normatif bağhllı̆̆a etkisi

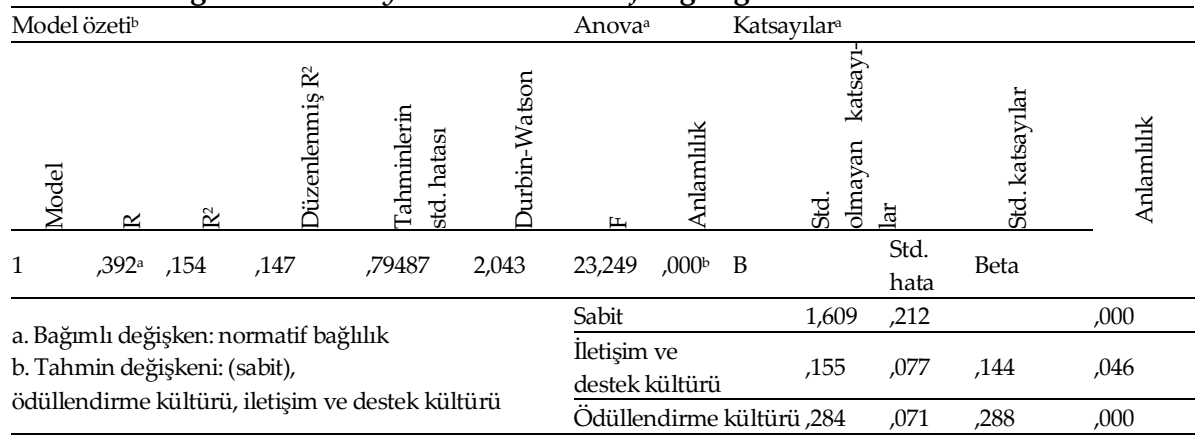

Örgüt kültürünün iletişim ve destek kültürü boyutu ve ödüllendirme kültürü boyutunun, örgütsel bağlllığın normatif bağlılık boyutu üzerindeki etkisini tespit edebilmek için yapılan regresyon analizi sonuçları Tablo 3.9' da yer almaktadır. Bulgulara doğrultusunda ödüllendirme kültürü ile iletişim ve destek kültürünün normatif bağlllığa etkisinin \%14,7 (düzeltilmiş $R^{2}: 0,147$ ) olduğu görülmektedir. Regresyon modelinin anlamlılı̆̆ının test edilmesi için incelenen Anova değeri ise $p<0,05$ düzeyinde istatistiki olarak anlamlı bulunmuştur. Bunun yanında iletişim ve destek kültürü değişkeninin normatif 
bağlllı̆̆ arttırma düzey 0,144 (Std. Beta), ödüllendirme kültürünün duygusal bağlılığ1 arttırma düzeyi ise 0,288 (Std. Beta) olarak tespit edilmiştir. Elde edilen açıklama düzeylerinin istatistiki olarak anlamlı olduğu $(\mathrm{p}<0,05)$ görülmektedir. Son olarak değişkenler arasındaki otokorelasyonun varlığının kontrol edilmesi için kullanılan Durbin-Watson değerinin 2,043<3,000 düzeyinde olduğu tespit edilmiştir. Yani değişkenler arasında otokorelasyon olmadığı sonucuna ulaşılmıştır. Elde edilen bulgular genel olarak değerlendirildiğinde; örgütlerin uygun iletişim ve destek kültürüne sahip olması, çalışanların normatif bağlılığını arttırma konusunda faydalıdır. Çalışanların normatif bağlllıklarının artmasında ödüllendirme kültürünün daha önemli bir unsur olduğu da görülmektedir. Elde edilen bulgular doğrultusunda "H1cve H1d" hipotezleri desteklenmiştir.

Tablo 3.10. Örgüt kültürï boyutlarının devam bağhllı̆ına etkisi

\begin{tabular}{|c|c|c|c|c|c|c|c|c|c|c|c|c|}
\hline \multicolumn{6}{|c|}{ Model özeti } & \multicolumn{2}{|c|}{ Anova $^{\mathrm{a}}$} & \multicolumn{5}{|c|}{ Katsayılara $^{\mathrm{a}}$} \\
\hline $\begin{array}{l}\frac{\bar{g}}{\delta} \\
\sum\end{array}$ & $\simeq$ & $\approx$ & 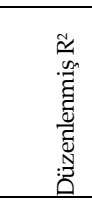 & 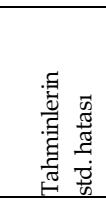 & 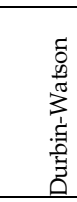 & 工 & $\begin{array}{l}\text { 首 } \\
\text { 自 } \\
\text { 定 }\end{array}$ & & 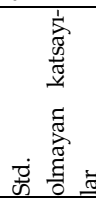 & & 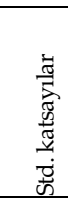 & 晜 \\
\hline 1 & $164^{\mathrm{a}}$ &, 027 &, 023 & 78088 & 2,042 & 7,134 &, $008^{b}$ & B & & $\begin{array}{l}\text { Std. } \\
\text { hata }\end{array}$ & Beta & 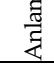 \\
\hline \multicolumn{6}{|c|}{ a. Bağımlı Değişken: Devam Bağlılığı } & \multicolumn{2}{|l|}{ Sabit } & 2,687 & & ,207 & &, 000 \\
\hline \multicolumn{6}{|c|}{$\begin{array}{l}\text { b. Tahmin değişkeni: (sabit), } \\
\text { ödüllendirme kültürü, iletişim ve destek kültürü }\end{array}$} & \multicolumn{2}{|c|}{$\begin{array}{l}\text { İletişim ve } \\
\text { destek kültürü }\end{array}$} & ,162 & &, 061 & 164 & ,008 \\
\hline
\end{tabular}

Örgüt kültürünün iletişim ve destek kültürü boyutunun, örgütsel bağlll1ğın devam bağllı̆̆ı boyutu üzerindeki etkisini tespit edebilmek için yapılan regresyon analizi sonuçları Tablo 3.10'da yer almaktadır. Bulgulara doğrultusunda iletişim ve destek kültürünün devam bağlllığına etkisinin \%2,3 (düzeltilmiş $R^{2}: 0,023$ ) olduğu görülmektedir. Regresyon modelinin anlamlılı̆̆1nın test edilmesi için incelenen Anova değeri ise $p<0,05$ düzeyinde istatistiki olarak anlamlı bulunmuştur. Bunun yanında iletişim ve destek kültürü değişkeninin devam bağlılı̆̆ını arttırma düzey 0,061 (Std. Beta) olarak tespit edilmiştir. Elde edilen açıklama düzeylerinin istatistiki olarak anlamlı olduğu $(p<0,05)$ görülmektedir. Son olarak değişkenler arasındaki otokorelasyonun varlığının kontrol edilmesi için kullanılan Durbin-Watson değerinin 2,042<3,000 düzeyinde olduğu tespit edilmiştir. Elde edilen sonuca göre de- 
ğişkenler arasında otokorelasyon olmadığı sonucuna ulaşılmıştır. Çalışanların örgütlerine devam etme açısından bağlılıklarının sağlanmasında ödüllendirme kültürünün etkisi bulunmazken, iletişim ve destek kültürünün çok düşük düzeyde bir etkisinin olduğu görülmektedir. Elde edilen bulgular genel olarak değerlendirildiğinde; örgüt içinde uygun iletişim ve destek kültürünün oluşturulması, çalışanların örgütlerinde kalmaya dayalı bağlılıklarında az da olsa etkili olacaktır.

Örgüt kültürünün alt boyutlarının örgütsel bağlılık alt boyutları üzerindeki etkisi hakkında elde edilen bulgular genel olarak incelendiğinde ise; çalışanların duygusal ve normatif açıdan bağlılıklarının artmasında ödüllendirme kültürünün iletişim ve destek kültüründen daha önemli olduğu görülmektedir. Öyle ki; çalışanların maddi ve içsel olarak ödüllendirilmeleri, onların duygusal ve değerler açısından örgüte bağlanmalarında önemlidir. Bunun yanında daha iyi alternatiflerin olmamasından kaynaklı olarak örgütte devam etme niyeti (devam bağlllığı) açısından ödüllendirme kültürünün anlamlı bir etkisi bulunmamaktadır. Çalışanların devam bağlılı̆̆ının sağlanmasinda iletişim ve destek kültürünün önemli olduğu görülmektedir. Elde edilen bulgular doğrultusunda " $\mathrm{H}_{1}$ " hipotezi desteklenirken " $\mathrm{H}_{1 \uparrow}$ " hipotezi desteklenememiştir.

Tablo 3.11. Örgüt kültürünün örgütsel bağhllk üzerindeki etkisi

\begin{tabular}{|c|c|c|c|c|c|c|c|c|c|c|c|c|}
\hline \multicolumn{6}{|c|}{ Model Özeti $^{\mathrm{b}}$} & \multicolumn{2}{|c|}{ Anova $^{a}$} & \multicolumn{4}{|c|}{ Katsayılara $^{\mathrm{a}}$} & \multirow{3}{*}{$\begin{array}{l}\text { 兰 } \\
\text { 䲶 } \\
\text { 至 }\end{array}$} \\
\hline$\frac{\bar{\Xi}}{\frac{8}{0}}$ & $\simeq$ & $\approx$ & 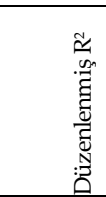 & 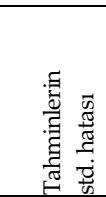 & 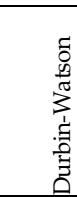 & 工 & 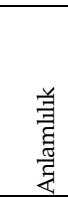 & & 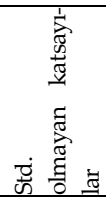 & & 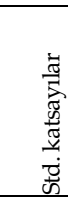 & \\
\hline 1 &, $494^{\mathrm{a}}$ & 244 & ,242 & 65017 & 2,024 & 83,161 &, $000^{\mathrm{b}}$ & B & & $\begin{array}{l}\text { Std. } \\
\text { hata }\end{array}$ & Beta & \\
\hline \multirow{2}{*}{\multicolumn{6}{|c|}{$\begin{array}{l}\text { a. Bağımlı değişken: Örgüt kültürü } \\
\text { b. Tahmin değişkeni: (sabit), Örgütsel bağlllık }\end{array}$}} & & & Sabit & 1,249 & ,202 & & , 000 \\
\hline & & & & & & Örgüt & zültürü & & 606 & ,066 & 494 &, 000 \\
\hline
\end{tabular}

Örgüt kültürünün örgütsel bağlllık üzerindeki etkisini tespit edebilmek için yapılan regresyon analizi sonuçları Tablo 3.11'de yer almaktadır. Bulgulara doğrultusunda örgüt kültürünün örgütsel bağlllık üzerindeki etkisinin $\% 24,2$ (düzeltilmiş $R^{2}: 0,242$ ) olduğu görülmektedir. Regresyon modelinin anlamlılığının test edilmesi için incelenen Anova değeri ise $p<0,05$ düzeyinde istatistiki olarak anlamlı bulunmuştur. Bunun yanında örgüt kültürü değiş- 
keninin örgütsel bağlllı̆g arttırma düzey 0,494 (Std. Beta) olarak tespit edilmiştir. Elde edilen açıklama düzeylerinin istatistiki olarak anlamlı olduğu $(p<0,05)$ görülmektedir. Son olarak değişkenler arasındaki otokorelasyonun varlığının kontrol edilmesi için kullanılan Durbin-Watson değerinin 2,042<3,000 düzeyinde olduğu tespit edilmiştir. Elde edilen sonuca göre değişkenler arasında otokorelasyon olmadığı sonucuna ulaşılmıştır. Son olarak örgüt kültürünün örgütsel bağlllığa etkisi hakkındaki bulgular genel olarak yorumlanacak olursa; çalışanların örgütlerine olan bağlllıklarının artmasinda örgüt kültürünün önemli bir faktör olduğunu ifade etmek mümkündür. Örgütün çalışanları ile bilgi alışverişini sağlıklı olarak yürütecek bir kültüre sahip olmaları, çalışanları içsel ve maddi açıdan yeterince destekleyecek bir örgütsel kültüre sahip olmaları çalışanların örgüte olan bağlılıklarını arttıracak attıracaktır. Elde edilen bulgular doğrultusunda " $\mathrm{H}_{1}$ " hipotezi desteklenmiştir.

\section{Sonuç, Tartışma ve Öneri}

Örgüt kültürünün çalışanların örgütsel bağlllıklarına etkisini tespit edebilmek amacıyla yapılan bu araştırmada sağlık sektörü çalışanlarıyla bir alan araştırması gerçekleştirilmiştir. Analizlerin sonucunda şu bulgulara ulaşılmıştır; örgütlerdeki iletişim ve destek kültürünün ve ödüllendirme kültürünün çalışanların bulundukları örgüte duygusal açından bağlılıklarını arttırmaktadır. Ödüllendirme kültürünün etkisinin iletişim ve destek kültürüne göre duygusal bağlılığı daha yüksek düzeyde etkilediği sonucuna ulaşılmıştır. Örgütlerde dizayn edilen ödüllendirme kültürünün ve iletişim-destek kültürünün çalışanların normatif bağlılıklarını olumlu yönde etkilediği sonucuna ulaşılmıştır. İletişim ve destek kültürünün devam bağl1lı̆ıını arttırdığ sonucuna ulaşılmıştır. Bütün olarak bakıldığında örgüt kültürünün örgütsel bağlılığ1 artırdığı sonucuna ulaşılmıştır. Örgütte herkese bilgi yayılmasını sağlayacak ve çalışanları destekleyecek bir örgüt yapısının oluşturulması, çalışanların örgütte devam etmelerini, örgüte duygusal açıdan bağllık duymalarını ve örgütte inanç açısından bağlılık duymalarını sağlayabilecektir. Bunun yanında örgütün kültürünün ödüllendirici özellikte olması, çalışanların örgütlerine duygusal yönden ve inanç yönünden bağll1ıklarını sağlayabilmektedir. Araştırma sonucunda örgüt kültürünün çalışanların örgüte bağll- 
lıklarını arttırdığını ifade etmek mümkündür. Araştırmada elde edilen sonuçlar ile alanyazındaki çalışma sonuçları tutarlıdır. Bu araştırmadaki hali ile örgüt kültürü ölçeğinin kullanıldığı Aydın vd. (2016) tarafından yapılan çalışmada da örgüt kültürü ile örgütsel bağlılık arasında olumlu yönde ilişkiler olduğu tespit edilmiştir. Bunun yanında söz konusu araştırmada nedensellik ilişkilerinin incelenmediği görüldüğünden bu araştırmada elde edilen nedensellik ilişkileri ile Aydın vd. (2016) tarafından yapılan çalışmanın sonuçları tam olarak karşılaştırılamamaktadır. Alanyazında örgüt kültürünün genellikle örgütsel bağllığı arttırdığ1 yönünde sonuçların (Erdem, 2007; Widyaningrum 2012; Akyürek vd. 2013; Kolancioğlu ve Karabulut, 2018) mevcut olması ise, elde edilen sonucun genellenebilirliğini göstermek açısından önemlidir. Örgütün kültürünün çalışan yönelimli olması, yani; çalışanları destekleyici, çalışanların diğer çalışanlarla olan iletişimlerini sağlayıcı ve çalışanların ödüllendirilmesini sağlayıcı özellikte dizayn edilmesi, çalışanların normlar açısından, duygusal olarak ve örgütte kalma niyetleri açısından fayda sağlayacaktır. Elde edilen sonuçların özellikle Covid-19 bağlamında önemli olduğunu ifade etmek mümkündür. Özellikle, bu dönemde sağlık personellerinin büyük riskler altında çalıştıkları göz ününe alınırsa, örgüt kültürünün çalışanlara yönelik oluşturulmasının ne denli önemli sonuçlar verebileceği göz ardı edilememelidir. Özellikle elde edilen sonuçların farklı sektörlerde test edilmesi, elde edilecek sonuçların farklılaşmasına neden olabilecektir. Bunun yanında çalışmanın farklı veri toplama araçları ile tekrarlanması (örn; mülakat), ödüllendirme kültürünün neden devam bağl1lı̆̆1 üzerinde anlamlı bir etkisi olmadığını da açıklayabilecektir. 


\section{EXTENDED ABSTRACT}

\section{The Effect of Organizational Culture on Organizational Commitment: A Research in Health Sector

\author{
$*$ \\ Gülşah Gençer Çelik \\ Beyketn University
}

It is known that employees have an important place in achieving and maintaining a competitive advantage. It is important in this respect that the talents of the employees are preserved within the organization. One way employees stay in the organization is through increasing their commitment to the organization. Such that; Employees 'willingness to stay in the organization for whatever reason will contribute to the organizations' ability to compete in their sector. According to the results of the studies in the literature, the culture of the organizations is an element that increases the commitment of the employees to the organization. In these studies, it was concluded that the cultural characteristics of the organizations positively affect the employees' emotional commitment to the organization in terms of principles or the absence of alternatives.

Aim of the research; Within the scope of this research, it is aimed to determine the effect of organizational culture on organizational commitment. In the research, a field study is carried out in terms of the health sector. Findings to be obtained as a result of the research; The communication and support culture and rewarding culture of the organization are essential in explaining the emotional, normative, and continuous commitment of employees to their organizations.

The method of the research; The sample of the study is nurses working in the health sector in Istanbul. Research the sample, 300 out of 400 people working in a private health institution were given a questionnaire. 259 of the 300 forms distributed were filled. Simple random sampling technique was used to determine the sample. A questionnaire form consisting of three parts was used in the study. In the first part of my questionnaire, five questions were asked to determine the participants' demographic characteristics. Consisting 
of 12 items representing the organizational culture and three main dimensions, Aydin et al. The measurement tool created by (2016) was used. The measurement tool created by Allen and Meyer (1990) was used to measure organizational commitment. The organizational commitment scale consists of 18 items and three dimensions.

Findings of the research; Firstly, factor analysis and reliability analysis were performed in the research. As a result of the factor analysis, the KMO value of the organizational culture scale was 0.886 , and the total variance explained was $63.55 \%$. The KMO value of the organizational culture scale was 0.846 , and the total variance explained was $61.34 \%$. As a result of the reliability analysis of the organizational culture scale; While the Cronbach's Alpha coefficient was determined as 0.909 , there were 12 items on the scale. Cronbach's Alpha coefficient of the organizational commitment scale was determined as 0.844 . Also, there were 16 items in the measurement tool.

Correlation analysis was carried out in order to test the relationships between variables. As a result of correlation analysis, between the sub-dimensions of organizational culture and the sub-dimensions of organizational commitment; Positive and statistically significant relationships were determined at different levels. According to the regression analysis results; The effect of rewarding culture \& communication and support culture on emotional commitment is $25.1 \%$ (adjusted R2: 0.251 ). The effect of rewarding culture and communication and support culture on normative commitment is $14.7 \%$ (adjusted R2: 0.147). The effect of communication and support culture on attendance commitment is $2.3 \%$ (adjusted R2: 0.023). The rewarding culture does not affect attendance commitment. It is seen that the effect of organizational culture on organizational commitment is $24.2 \%$ (corrected R2: 0.242 ).

According to the research results, it is possible to say that the organizational culture increases the commitment of the employees to the organization. The results obtained in the research and the results of the study in the literature are consistent. However, there are few studies conducted with organizational culture measurement tools that include the communication and support dimension and rewarding dimension in the literature. In the study conducted by Aydin et al. (2016), in which the organizational culture scale was used, it was found that there were positive relationships between organizational culture and organizational commitment. Also, since it was seen that 
causality relationships were not examined in the study in question, the causality relationships obtained in this study and the results of the study conducted by Aydin et al. (2016), cannot be compared precisely.

It would be appropriate to examine the results obtained in the context of healthcare professionals and the Covid-19 pandemic. Testing the results obtained in different sectors may cause the results to be differentiated. Also, repeating the study with different data collection tools (e.g., interview) may explain why the rewarding culture does not significantly affect attendance commitment.

\section{Kaynakça/References}

Akyürek, Ç. E., Toygar, Ş. A. ve Şener, T. (2013). Örgütsel kültür ve alt kültürün örgütsel bağlllığa etkisi: Sağlık çalışanları üzerine bir araştırma. Ankara Sağllk Hizmetleri Dergisi, 12(2), 55-62.

Allen, N. J. ve Meyer, J. P. (1990). The measurement and antecedents of affective, continuance and normative commitment to th organisation. Journal Of Occupational Psychology, 63, 1-18.

Allen, N. J. ve Meyer, J. P. (1993). Organizational commitment: Evidence of career stage effects? Journal of Business Research, 26(1), 49-61.

Arbak, Y. ve Kesken J. (2005). Örgütsel bağlllk, sağhlk hizmetlerinde sürekli gelişim için davramışsal bir yaklaşım. Dokuz Eylül Üniversitesi Yayınları, İzmir,

Aydın, Ö., Akın, D., Gönen Dede, F., Bilgili, M. E. ve Kaplan, D. (2016). Kamu hastanesinde örgüt kültürü ve örgütsel bağlllık ilişkisi. Uluslararası Sağlı Yönetimi ve Stratejileri Araştırma Dergisi, 2(1), 25-43.

Chen, Y. L. (2004). Examining the effect of organization culture and leadership behaviors on organizational commitment, job satisfaction, and job performance at small and middle-sized firms of Taiwan. The Journal of American Academy of Business, Cambridge, September, 432-438.

Çavuş, Ş. ve Gürdoğan, A. (2008). Örgüt kültürü ve örgütsel bağlllık ilişkisi: Beş ylldızlı bir otel işletmesinde araştırma. Ticaret ve Turizm Eğitim Fakültesi Dergisi, $1,18-34$.

Demir, C. ve Öztürk, U. C. (2011). Örgüt kültürünün örgütsel bağlllık üzerine etkisi ve bir uygulama. Dokuz Eylül Üniversitesi İktisadi ve İdari Bilimler Fakültesi Dergisi, 26(1), 17-41.

Diker, O. (2014). Alg̨lanan liderlik tarzlar, örgüt kültürü ve örgütsel bağhllk ilişkisinin turizm endüstrisinde incelenmesi. Doktora Tezi, Eskişehir Osmangazi Üniversitesi Sosyal Bilimler Enstitüsü, Eskişehir. 
Erdem, R. (2007). Örgüt kültürü tipleri ile örgütsel bağlllık arasındaki ilişki: Elazığ il merkezindeki hastaneler üzerinde bir çalışma. Osmangazi Üniversitesi, İktisadi ve İdari Bilimler Fakültesi Dergisi, 2(2), 63-79.

Fettahlığlu, Ö. O. ve Tatlı, H. S. (2015). Örgütsel bağlllık ve farklılıkların yönetimi algılamaları arası ilişkilerin saptanmasında demografik farklılıklara yönelik inceleme. Kahramanmaraş Sütçü İmam Üniversitesi, Sosyal Bilimler Dergisi,12(2), 119-140.

George, D. ve Mallery, M. (2010). Spss for windows step by step: A simple guide and reference, 17.0 update (10a ed.) Boston: Pearson.

Gülova, A. A. ve Demirsoy, Ö. (2012). Örgüt kültürü ve örgütsel bağlllık arasındaki ilişki: Hizmet sektörü çalışanları üzerinde ampirik bir araştırma, Business And Economics Research Journal, 3(3), 49-76.

Hair J.F. Jr., Anderson R.E., Tatham R.L. ve Black W.C. (2014). Multivariate data analysis. New York, Macmillan.

Handy, C. B. (1995). Gods of management: The changing work of organizations. Oxford University Press.

Kantek, F. ve Kurnaz, H. (2018). Türkiye'de hastane örgüt külttürünü inceleyen çalışmalara bakış. Sağllk ve Hemşirelik Yönetimi Dergisi, 5 (3), 201-209.

Kaya, H. (2008). Kamu ve özel sektör kuruluşlarının örgütsel kültürünün analizi ve kurum kültürünün çalışanların örgütsel bağlllı̆̆na etkisi: Görgül bir araştirma. Maliye Dergisi, 115, 119-143.

Kolancıoğlu, B. ve Karabulut, A. T. (2018). Örgüt kültürünün örgütsel bağllllk üzerindeki etkisi: Hastaneler üzerinde bir araştırma. İstanbul Ticaret Üniversitesi Sosyal Bilimler Dergisi, 17(33), 115-131.

Koşar, S. ve Çalık, T. (2011). Okul yöneticilerinin yönetimde gücü kullanma stilleri ile örgüt kültürü arasındaki ilişki. Kuram ve Uygulamada Eğitim Yönetimi, 17(4), 581-603.

Meyer, J. P. ve Allen, N. J. (1991). A three-component conceptualization of organizational commitment. Human Resource Management Review, 1(1), 61-89.

Mowday, R. T., Steers, R. M. ve Porter, I. W. (1979). The measurement of organizational commitment. Journal of Voctional Behavior, 14(7), 224- 247.

Öngel, G. (2018). Sağhlk çalışanlarının yaşamış olduklan iş-aile yaşamı çatışmasının örgütsel bağ̆llık, iş doyumu ve işten ayrılma niyetine etkisi. Yayınlanmamış Doktora Tezi, Beykent Üniversitesi, Sosyal Bilimler Enstitüsü, İstanbul.

Özata, M. (2015). Hastanelerde görev yapan sağlık çalışanlarının örgütsel bağlllık düzeylerinin belirlenmesi. Selçuk Üniversitesi Sosyal Bilimler Meslek Yüksekokulu Dergisi, 18(1), 155-166. 
Sezgin, F. (2010). Öğretmenlerin örgütsel bağlllı̆̆ının bir yordayıcısı olarak okul kültürü. Eğitim ve Bilim Dergisi, 35(156), 142-159.

Tabachnick, B. G. ve L. S. Fidell (2013). Using multivariate statistics (Sixth ed.). Pearson, Boston.

Toker, B., Çevirgen, A. ve Kalıpçı, M. B. (2019). Örgüt kültürünün örgütsel bağlllı̆̆a etkisi: Seyahat acentaları üzerinde bir uygulama. Organizasyon ve Yönetim Bilimleri Dergisi, 11(2), 38-53.

Wasti, S. A. (2000). Meyer ve Allen üç boyutlu örgütsel bağllllk ölçeğinin geçerlilik ve güvenirlilik analizi. 8. Ulusal Yönetim ve Organizasyon Kongresi Bildirileri, 401410.

Widyaningrum, M. E. (2012). Effects of organizational culture and ability on organizational commitment and performance in Ibnu Sina Hospital Gresik. Academic Research International, 2(1), 349-355.

Yıldız, S. (2017). Örgüt kültürü̈ ve örgütsel bağhllk ilişkisi: İstanbul üniversitesi İstanbul tıp fakültesi hastanesi örneği. İstanbul Gelişim Üniversitesi Sosyal Bilimler Enstitüsü, Yayınlanmamış Yüksek Lisans Tezi, İstanbul.

Yılmaz, F, Pülat, R. ve Söyük, S. (2020). Sağlık çalışanlarında örgütsel sessizlik ve örgüt kültürü ilişkisi üzerine bir inceleme. Social Sciences Research Journal, 9(3), $1-20$.

Yılmaz, S. (2019). Örgüt kültürü ve örgütsel bağllllk ilişsisi. Ed. S. Sönmez vd., Sosyal Beşeri ve İdari Bilimler Alanında Yeni Ufuklar-4 içinde (s.255-263)., Gece Akademi, Ankara.

\section{Kaynakça Bilgisi / Citation Information}

Gençer Çelik, G. (2021). Örgüt kültürünün örgütsel bağlllığa etkisi: Sağlık sektöründe bir araştırma. OPUS-Uluslararası Toplum Araştırmaları Dergisi,17(36), 2740-2766. DOI: 10.26466/opus.858804 